\title{
Detection of irradiation induced changes on the activity and diversity of soil microbial communities: The effect of soil type
}

\author{
N.R. Parekh, E.D. Potter, J.S. Poskitt, B.A. Dodd and N.A. Beresford \\ Centre for Ecology and Hydrology, Lancaster Environment Centre, Library Avenue, Bailrigg, \\ Lancaster LA1 4AP, UK
}

\begin{abstract}
Our aim was to measure the effects of irradiation treatments on soil communities from three different soils. Undisturbed soil cores from three temperate sites (deciduous and coniferous woodland and grassland) were irradiated to give cumulative doses from 0-160 Gy. Cores were incubated at $15^{\circ} \mathrm{C}$ and three cores from each treatment sampled after $<1,3$ and $8 \mathrm{~d}$. Soil fungi and heterotrophic bacteria were enumerated and the activity and functional diversity of soil microbial communities assessed in terms of their potential to utilise a range of $\mathrm{C}$-sources. Although no significant treatment effects were observed in the numbers of cultivable fungi or fast growing heterotrophic bacteria, the numbers of cultivable Pseudomonas spp. declined in all three soils after irradiation at 80 and $160 \mathrm{~Gy}$. Microbial communities from the coniferous forest soil also showed a dramatic decrease in the metabolic activity and number of substrates utilised by after irradiation at $160 \mathrm{~Gy}$. Gamma irradiation had a greater affect on microbial communities in the two organic forest soils as compared to the mineral grassland soil, this could be related to variations in the physico-chemical shielding properties and in the indigenous communities in terms of radio-resistant species.
\end{abstract}

\section{INTRODUCTION}

Alterations to soil microbial community structure and function occur in the presence of a range of pollutants and disturbances e.g. hydrocarbons [1], heavy metals [2] and microwaves [3]. Soil microorganisms have recently been highlighted as potential reference organisms for consideration within frameworks for the protection of the environment from ionising radiation. Previous work on the perturbation of soil microbial communities by ionising radiation has mainly focussed on the impacts of high doses $(\mathrm{kGy})$ designed to sterilise soil for the purpose of transportation between countries and for soil research experiments [4]. A study conducted in the aftermath of the Chernobyl accident indicated that the prokaryotic microbes exhibited reduced species richness in a $10 \mathrm{~km}$ zone around the reactor [5]. Few studies have attempted to evaluate the effects of either acute or chronic exposure to $\gamma$-radiation on indigenous microbial communities at doses which are representative of those encountered in the vicinity of storage repositories and low level fallout scenarios. Impacts of irradiation in the range of 10 to 400 Gy on cultivable organisms have been recorded [4].

Microbiological activity within a soil is largely dictated by microbial biomass and more importantly by the physiological activity and functional diversity of this biomass. We argue that it is the microbial diversity at a functional level which is important for long-term stability of an ecosystem, rather than diversity at a taxonomic level. One simple approach to evaluating functional diversity of a microbial community is based on the ability of members of the community to utilize different substrates. This culture-based approach using $\mathrm{BIOLOG}^{\mathrm{TM}}$ technology relates only to a small proportion of the soil microbial community, namely the fast growing heterotrophs. Although, the limitations of the BIOLOG ${ }^{\mathrm{TM}}$ system are widely acknowledged, substrate utilization patterns provide information on function and diversity of microbial communities [6]. 
A study to compare the effect of single comparatively (cf. previous studies) low level irradiation on soil microbial communities is described.

\section{MATERIALS AND METHODS}

\subsection{Soil sampling and irradiation}

Soil samples were collected from Meathop Wood (deciduous woodland, GB NGR SD437795), Grizedale Forest (coniferous forest, NGR SD326913) and Nottingham (grassland, NGR SK539383) in October 2000.

Cores were collected from each of the three sampling sites to depth of $12 \mathrm{~cm}$ and transported to the University of Nottingham under cooled conditions. Doses of $\gamma$-radiation $\left(7.0 \mathrm{~Gy} \mathrm{~min}^{-1}\right)$ were applied using a sealed ${ }^{137} \mathrm{Cs}$ source the total dose being determined by irradiation time. Nine cores were used for each irradiation level, the irradiation levels were 0 (control), 2.5, 5, 10, 40, 80 and $160 \mathrm{~Gy}$.

The cores were then returned to the laboratory in cool boxes where they were incubated at $15^{\circ} \mathrm{C}$ for up to $8 \mathrm{~d}$. Three cores were destructively sampled after $<1 \mathrm{~d}, 3 \mathrm{~d}$ and $8 \mathrm{~d}$. Soils were wet sieved $(2 \mathrm{~mm}$ mesh) as soon as possible after sampling. For microbiological analyses, $2 \mathrm{~g}$ fresh weight ( $\mathrm{fw}$ ) of each sample was weighed into a sterile centrifuge tube for immediate extraction of fungi and bacteria. Approx. $1 \mathrm{~g}$ fw of each sample dried to constant weight at $105^{\circ} \mathrm{C}$ (overnight) to determine the moisture content. Aseptic techniques were used throughout.

\subsection{Extraction and enumeration of soil fungi}

Ten $\mathrm{ml}$ of $1 / 4$ Ringer's solution was added to $2 \mathrm{~g}$ fw of soil in a centrifuge tube. The tube was shaken on a rotating shaker at $4^{\circ} \mathrm{C}$ for $10 \mathrm{~min}$ then allowed to stand for $1 \mathrm{~min}$. The soil extract supernatant was used to prepare a tenfold serial dilution series in $1 / 4$ strength Ringer's solution up to $10^{-4}$. Each dilution was shaken by hand and $1 \mathrm{ml}$ dispensed into a sterile, empty petri plate. Molten, cooled potato dextrose agar (PDA, $20 \mathrm{ml}+200 \mu \mathrm{l}$ streptomycin to inhibit bacterial growth) was pored onto the soil solution and the plate swirled to distribute the inoculum and agar. Plates were allowed to set before being incubated upside down at $20^{\circ} \mathrm{C}$. Fungal colonies were counted after 4,7 and $10 \mathrm{~d}$.

\subsection{Extraction, enumeration and assessment of functional diversity of soil bacterial communities}

The above soil extract was shaken using a vortex shaker for $1 \mathrm{~min}$ and allowed to stand for a further $1 \mathrm{~min}$. The soil extract supernatant was used to prepare a tenfold serial dilution series in $1 / 4$ strength Ringer's solution up to $10^{-5}$. The $10^{-2}$ dilution was made up to $50 \mathrm{ml} \mathrm{in} 1 / 4$ strength Ringer's solution to allow for inoculation of BIOLOG GN2 microplates.

Soil extract dilutions $(100 \mu$ l of each) were spread plated onto R2A Agar, Tryptone Soya Broth Agar (TSBA) and Pseudomonas Agar (PA) + CFC Supplement. R2A is a nutrient poor medium and TSBA is a nutrient rich medium, both are general, non-specific media for the growth of heterotrophic bacteria; both media were supplemented with $50 \mu \mathrm{g} / \mathrm{ml}$ cycloheximide to prevent fungal growth. PA with CFC (Cetrimide, Fucidin and Cephalosporin) supplement is a specific medium for the isolation of Pseudomonas species. Agar plates were incubated upside down at $20^{\circ} \mathrm{C}$ and colony forming units (cfu) were counted after 4, 7 and $10 \mathrm{~d}$ of incubation. Colonies on PA which fluoresced under a UV light were counted as those of fluorescent pseudomonads.

Each well of the BIOLOG microplates was inoculated with $150 \mu \mathrm{l}$ of the selected soil dilution $\left(10^{-2}\right.$ unless stated otherwise $)$ using a multipipettor. The plates were read after inoculation at day 0 and after incubation at $20^{\circ} \mathrm{C}$ for 3,7 and $10 \mathrm{~d}$ using a spectrophotometer and substrate utilisation patterns for each sample analysed statistically using analysis of variance (ANOVA) and principle component analysis (PCA). 


\section{RESULTS}

\subsection{Fungal and bacterial counts}

Counts of fungal colonies on PDA ranged from 4 to $7 \mathrm{log} \mathrm{cfu} \mathrm{g}^{-1} \mathrm{dw}$ soil with the lowest counts from Meathop soils and the highest in soils from Grizedale. There were no significant effects of any of the irradiation treatments on the numbers of fungal colonies counted in samples collected after treatment $(1 \mathrm{~d})$ or after 4 and $8 \mathrm{~d}$ following treatment $(\mathrm{p}=0.39)$.

The numbers of bacterial colonies isolated on R2A and TSBA were similar even though the two media are contrasting in nutritional terms. The numbers of bacteria on R2A and TSBA ranged from 4.9 to 7.3 and 5.9 to $7.4 \mathrm{log} \mathrm{cfu} \mathrm{g}^{-1}$ dry weight (dw) soil respectively. There were no significant differences between the numbers of bacteria isolated from the three different soils and also from soils with different irradiation treatments $(\mathrm{p}>0.05)$. The numbers of colonies counted in samples collected after treatment $(1 \mathrm{~d})$ or after 4 and $8 \mathrm{~d}$ following treatment also did not show any clear treatment or 'recovery' effects.

The number of fluorescent colonies (Pseudomonas spp.) isolated on PA ranged from below the detection limit to $4.8 \mathrm{log} \mathrm{cfu} \mathrm{g}^{-1} \mathrm{dw}$ soil (Figure 1), the detection limit was $<10 \mathrm{cfu} \mathrm{g}^{-1}$. In the forest soils from Grizedale and Meathop there was an absence of Pseudomonas spp. in cores sampled $1 \mathrm{~d}$ after irradiation at 80 and 160 Gy. Recovery of Pseudomonas spp. colonies was observed $4 \mathrm{~d}$ post irradiation in Meathop soil and $8 \mathrm{~d}$ post irradiation in Grizedale soil. Irradiation at lower levels $(2.5$ and $10 \mathrm{~Gy})$ did not cause a shift in numbers of pseudomonad colonies but treatment at 80 and 160 Gy led to a significant decrease in the number of colonies ( $<0.0001$ over all sites). The numbers of colony forming units from the Nottingham soil $1 \mathrm{~d}$ after treatment were tenfold lower in samples irradiated at 80 and 160 Gy than in the control samples, no recovery effect was seen in these soils.
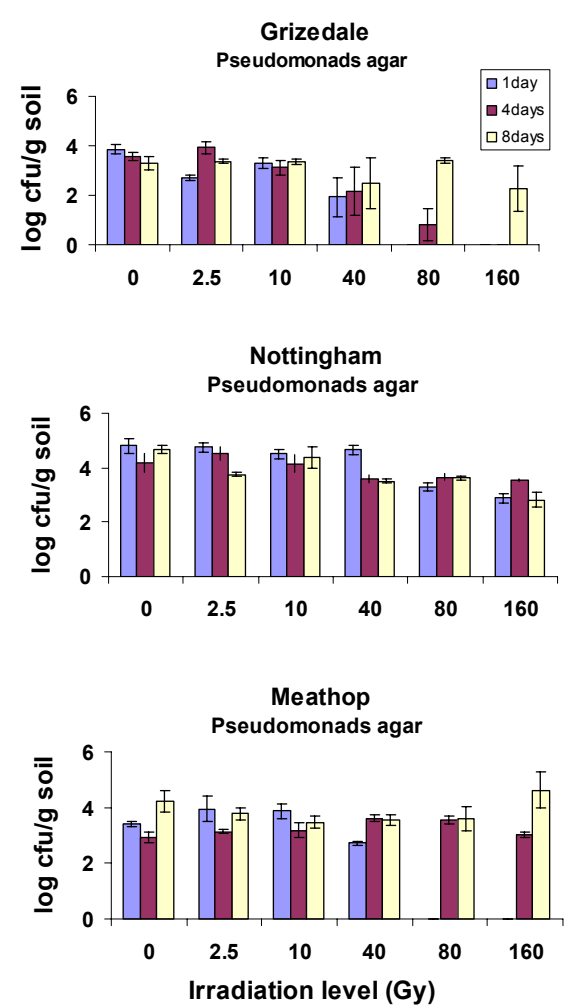

Figure 1. Numbers of Pseudomonas colonies after 1, 4 and $8 \mathrm{~d}$ following irradiation treatment in soils from three sites. Growth on PA plus CFC after $7 \mathrm{~d}$ incubation at $20^{\circ} \mathrm{C}$. 


\subsection{Community level physiological profiling}

The mean inoculum density of the suspensions used to inoculate the BIOLOG GN varied from 2.9 to $5.3 \log \mathrm{cfu} \mathrm{g}^{-1} \mathrm{dw}$ soil as determined on R2A. This variation was not reflected by the mean activities of the microbial communities i.e. samples with high inoculant densities did not always have high substrate utilisation activities and visa versa.

The effect of irradiation treatment on the rate of response to all 95 BIOLOG GN substrates as compared to the untreated soils is shown in Figure 2. Untreated soils from Grizedale had a significantly lower activity than soils from the other two sites. A decrease in the activity of communities from Grizedale was seen with increasing irradiation level in samples collected 1 and $4 \mathrm{~d}$ after treatment, $8 \mathrm{~d}$ post treatment the decrease in activity was only evident in samples which had been irradiated at $160 \mathrm{~Gy}$. The activity of soils from Meathop decreased after the highest irradiation treatment. Soils from the Nottingham site did not show any significant decrease in activity even after irradiation at the highest dose.

Samples from Nottingham and Meathop showed no the response in terms of metabolic diversity (the number of substrates utilised after $3 \mathrm{~d}$ incubation) with increasing irradiation treatment. Samples from these two sites showed a positive response towards all BIOLOG GN substrates. Control soils from Grizedale utilised 20-25\% less substrates than those from the other two soils and were more sensitive to irradiation treatment (Figure 3). Irradiation at $160 \mathrm{~Gy}$ led to a significant decrease $(p<0.05)$ in the average number of substrates used $1 \mathrm{~d}$ after irradiation; sustained 4 and $8 \mathrm{~d}$ post treatment.

Control 0 Gy

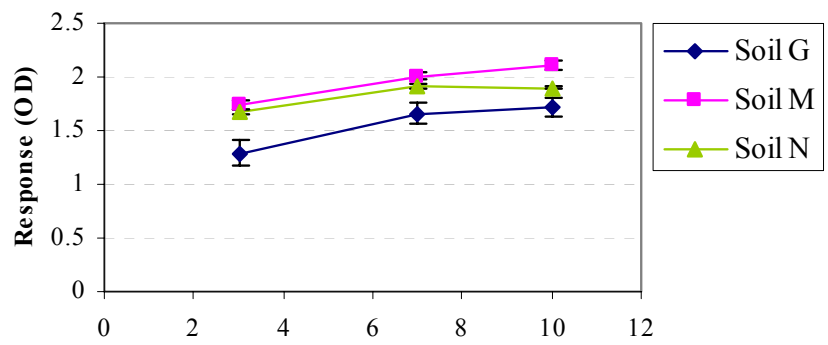

$160 \mathrm{~Gy}$

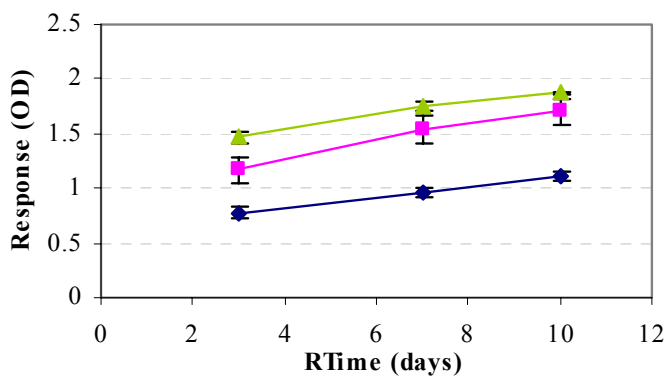

Figure 2. Average rate of response to all 95 BIOLOG GN substrates of microbial communities - control and 160 Gy soil samples from all 3 sites (Day 1 samples).

\section{DISCUSSION}

Acute irradiation at doses between 2.5 and 160 Gy led to no significant changes in the numbers of cultivable fungi or fast growing heterotrophic bacteria in the soils examined. Although doses as low as 10 Gy have been shown to alter soil fungal populations [7], previous work has demonstrated that kGy 
doses of irradiation are necessary to reduce numbers of culturable fungi in soil [4]. The numbers of cultivable Pseudomonas spp. showed a decline in samples from all 3 soils at doses of 80 and 160 Gy, this group has previously been shown as sensitive to $\gamma$-radiation [8]. The decline in Pseudomonas spp. was greatest in Grizedale samples which also showed a decrease in C-source use, both in terms of metabolic activity and diversity of substrates utilised, after irradiation at $160 \mathrm{~Gy}$. A reduction in numbers of Pseudomonas spp. as a result of $\gamma$-irradiation could lead to a loss in soil communities ability to process certain substrates and thus to a reduction in $\mathrm{C}$-cycling potential.

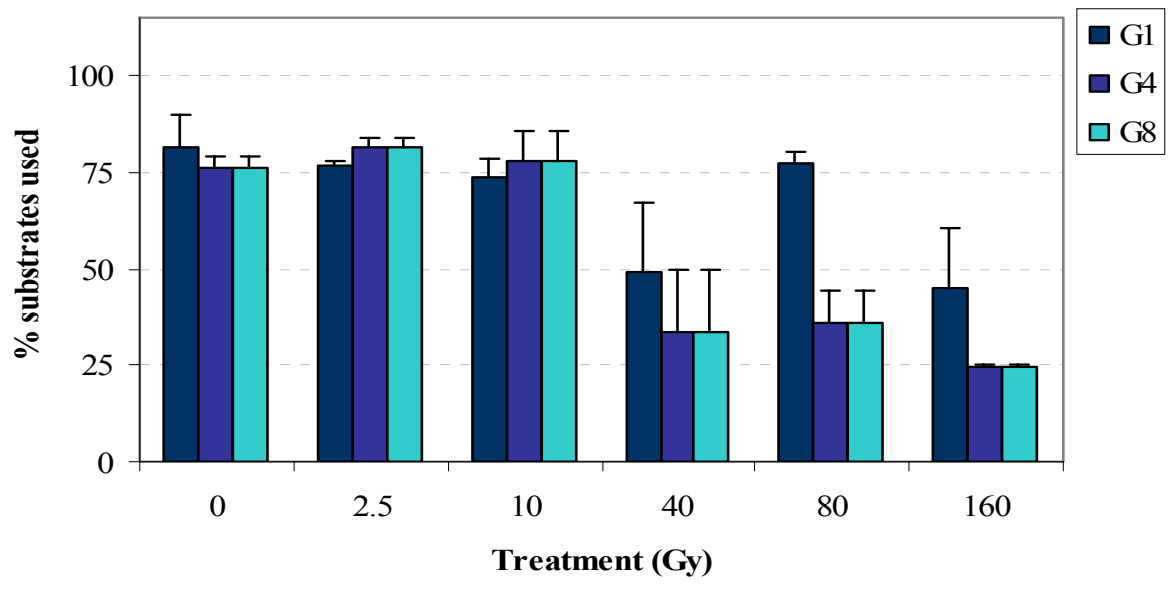

Figure 3. Effect of irradiation treatments on the metabolic diversity of samples after $3 \mathrm{~d}$ of incubation at $20^{\circ} \mathrm{C}$. Response of samples from Grizedale collected 1, 4 and $8 \mathrm{~d}$ after treatment (G1, G4 and G8 respectively in key).

The highest dose used in the current study was 160 Gy which resulted in a $36 \%$ reduction in the numbers of BIOLOG GN substrates used by Grizedale samples as compared with the non-irradiated soil. A $60 \%$ reduction in the number of substrates used after $\gamma$-irradiation at doses of 98 Gy compared to control samples has previously been observed for endothilic (rock inhabiting) microorganisms [9]. It was concluded that the reduction in cultivable bacteria and substrate use, may be due to both selective death of susceptible bacterial cells, and bacteria entering a viable but non-culturable state (VBNC).

The increase in numbers of culturable Pseudomonas spp. in Grizedale and Meathop samples after 4 and $8 \mathrm{~d}$ post-treatment, could be explained by an increase in radio-resistant populations. However, unlike previous observations [9], the growth of Pseudomonas spp. was not accompanied by an increase in the number of substrates utilised. This suggests that the post-irradiation Pseudomonas population in the Grizedale soils arose as a result of outgrowth of resistant strains and is not due to the resuscitation of cells which entered a VBNC state after treatment. Resuscitation can be a slow process and this short experiment may not have been long enough to detect restoration of VBNC cells.

Soil type plays an important role in determining the level of perturbation transmitted to the indigenous microbial communities. The order of affects on the indigenous soil microbial communities was Nottingham $<$ Meathop $<$ Grizedale and can be explained by two factors. Firstly, variations in $\gamma$-penetration through the different soils as a consequence of soil physicochemical characteristics and soil moisture. This would lead to differences in both the direct ionisation of cells and the indirect affects of radiation through formation of free radicals and peroxides [10]. Jackson et al. [11] reported that lower radiation doses eliminated microbial populations in wet soils than in dry soils due to the increased formation of free radicals in intra and extracellular fluids. Our results show that the affects of $\gamma$-irradiation on soil microbial communities are more pronounced in the two organic forest soils as compared to the more mineral grassland soil. Soil bulk densities increased in the order Grizedal $<$ Meathop $<$ Nottingham. Differences in the indigenous microbial communities in terms of radio-resistant species could also account for the variation in responses to perturbation. 


\section{Acknowledgements}

We would like to thank CEH for funding this work under the Integrated Fund.

\section{References}

[1] M.E. Fuller, K.M. Scow, S. Lau, H. Ferris, Soil Biol. Biochem., 2975 (1997).

[2] K.E. Giller, Soil Biol. Biochem., 301389 (1998).

[3] T.W. Speir, J.C. Cowling, G.P. Sparling, A.W. West, D.M. Corderoy, Soil Biol. Biochem., 18377 (1986).

[4] N.P. McNamara, H.I.J. Black, N.A. Beresford, N.R. Parekh, App. Soil Ecol., 24117 (2003).

[5] V.A. Romanovskaya, I.G. Sokolov, P.V. Rokitko, N.A. Chernaya, Microbiology, 67226 (1998).

[6] W. Hitzl, A. Rangger, S. Sharma, H. Insam, FEMS Microbiol. Ecol., 22167 (1997).

[7] G. Arunachalam,, G. Oblisami, G. Rangaswami, G. Madras Agr. J., 61, 992 (1974).

[8] V.A. Romanovskaya, P.V. Rokitko, A.N. Mikheev, N.I. Gushcha, Y.R. Malashenko, N.A. Chernaya, Microbiology, 71608 (2002).

[9] B.J. Pitonzo, P.S. Amy, M. Rudin, Radiation Res. 15264 (1999).

[10] V.A. Romanovskaya, P.V. Rokitko, Y.R. Malashenko, T.B. Krishtab, N.A. Chernaya, Microbiology, 68465 (1999).

[11] N.E. Jackson, J.C. Corey, L.R. Frederick, J.C. Picken Jr., Soil Science Soc. America, 31491 (1967). 